\title{
REKURSIVE FUNKTIONEN
}

V O N

Prof. Dr. RÓZSA PÉTER

EÖTVŎS LORĀND UNIVERSITĂT, BUDAPEST

ZWEITE, ERWEITERTE AUSGABE 
VERKAUF DIESES WERKES NUR IN DEUTSCHLAND GESTATTET

(C) 1957 by Akadémiai Kiadó, Budapest

Erschienen im Akadéniai Kiadó, Budapest, in Arbeitsgemeinschaft mit dem Akademie-Verlag GmbH., Berlin W 8, Mohrenstrasse 39 Lizenz-Nr. $202 \cdot 100 / 161 / 57$

Gesamtherstellung: Szegeder Druckerei, Szeged, Bestell- und Verlagsnummer 5264 Printed in Hungary 